\title{
Novel meso-substituted porphyrin derivatives and its potential use in photodynamic therapy of cancer
}

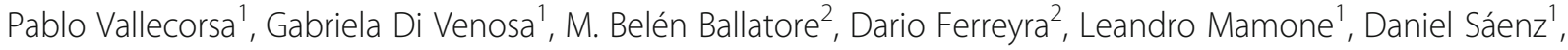
Gustavo Calvo ${ }^{1}$, Edgardo Durantini ${ }^{2}$ and Adriana Casas $^{1 *}$ (D)

\begin{abstract}
Background: Photodynamic therapy (PDT) is an anticancer treatment that utilizes the interaction of light and a photosensitiser (PS), promoting tumour cell death mediated by generation of reactive oxygen species. In this study, we evaluated the in vitro photoactivity of four meso-substituted porphyrins and a porphyrin coupled to a fullerene.

Methods: The cell line employed was the LM3 mammary adenocarcinoma, and the PS with the best photokilling activity was administered to mice bearing the LM3 subcutaneously implanted adenocarcinoma. The TEMCP ${ }^{4+}$ porphyrin and its analogue TEMCC ${ }^{4+}$ chlorine contain four identical carbazoyl substituents at the meso positions of the tetrapyrrolic macrocycle and have $\mathrm{A}_{4}$ symmetry. The TAPP derivative also has $\mathrm{A}_{4}$ symmetry, and it is substituted at the meso positions by aminopropoxy groups. The DAPP molecule has ABAB symmetry with aminopropoxy and the trifluoromethyl substituents in trans positions. The TCP- $\mathrm{C}_{60}{ }^{4+}$ dyad is formed by a porphyrin unit covalently attached to the fullerene $\mathrm{C}_{60}$.

Results: The PSs are taken up by the cells with the following efficiency: TAPP $>$ TEMCP ${ }^{4+}=$ TEMCC $^{4+}>$ DAPP $>$ TCP$\mathrm{C}_{60}{ }^{4+}$, and the amount of intracellular PS correlates fairly with the photodamage degree, but also the quantum yields of singlet oxygen influence the PDT outcome. TAPP, DAPP, TEMCC ${ }^{4+}$ and TEMCP ${ }^{4+}$ exhibit high photoactivity against LM3 mammary carcinoma cells, being TAPP the most active. After topical application of TAPP on the skin of mice bearing LM3 tumours, the molecule is localized mainly in the stratum corneum, and at a lower extent in hair follicles and sebaceous glands. Systemic administration of TAPP produces a tumour: normal skin ratio of 31.4, and high accumulation in intestine and lung.

Conclusion: The results suggest a potential use of topical TAPP for the treatment of actinic keratosis and skin adnexal neoplasms. In addition, selectivity for tumour tissue after systemic administration highlights the selectivity of and potentiality of TAPP as a new PS.
\end{abstract}

Keywords: Photodynamic therapy, Porphyrins, Cancer, Photosensitisers, Cells, Mice

\footnotetext{
* Correspondence: adricasas@live.com

${ }^{1}$ Centro de Investigaciones sobre Porfirinas y Porfirias (CIPYP), CONICET and Hospital de Clínicas Gral. José de San Martín, Universidad de Buenos Aires, Córdoba 2351 1er subsuelo, CP1120AAF Ciudad de Buenos Aires, Argentina Full list of author information is available at the end of the article
}

(c) The Author(s). 2021 Open Access This article is licensed under a Creative Commons Attribution 4.0 International License, which permits use, sharing, adaptation, distribution and reproduction in any medium or format, as long as you give appropriate credit to the original author(s) and the source, provide a link to the Creative Commons licence, and indicate if changes were made. The images or other third party material in this article are included in the article's Creative Commons licence, unless indicated otherwise in a credit line to the material. If material is not included in the article's Creative Commons licence and your intended use is not permitted by statutory regulation or exceeds the permitted use, you will need to obtain permission directly from the copyright holder. To view a copy of this licence, visit http://creativecommons.org/licenses/by/4.0/ The Creative Commons Public Domain Dedication waiver (http://creativecommons.org/publicdomain/zero/1.0/) applies to the data made available in this article, unless otherwise stated in a credit line to the data. 


\section{Background}

Photodynamic therapy (PDT) is a technique that involves the use of a photosensitising substance (PS), which after being irradiated with a suitable wavelength in the presence of oxygen, undergoes photoactivation and reacts with cellular molecules promoting cell death mediated by generation of reactive oxygen species [1]. PDT can be used as an anticancer therapy mainly in dermatology and other malignancies, among other applications [2, 3]. It has been suggested that certain characteristics of tumours, as well as the vasculature, promote differential uptake of the PSs and therefore, the selective action of PDT [4].

First-generation PSs, such as Photofrin, exhibit poor clearance and lacks long-wavelength absorption. The synthesis of second-generation PSs moved towards modified tetrapyrrolic compounds, such as benzoporphyrin, chlorin and porphycene, which have a more intense long-wavelength absorption [5]. However, there is still an increasing need to develop new PSs showing better tumour selectivity, less cutaneous photosensitisation and increased photoactivity. Adequate PSs are expected to have a high absorption coefficient in the visible region of the spectrum and efficiently produce singlet oxygen [6].

The chemical structure of a PS plays a main role in the photosensitisation efficacy. An ideal PS has to be soluble in physiological media, and the degree of hydrophilicity and amphiphilicity directly influence the administration route, its biodistribution/pharmacokinetic profile and tumour selectivity [5].

Cationic porphyrins have several interesting features due to better solubilization in aqueous media and interaction with the cell membrane than their uncharged analogs, which make them attractive PSs. Besides, in recent years the meso-substituted porphyrins have gained interest in many areas of science and technology [7, 8].

Fullerenes have attracted considerable attention in different fields of science. Their unique carbon cage structure coupled with immense scope for derivatization make them a potential therapeutic agent. The fullerene family, especially C60, has unique photochemical and electrochemical properties that can be exploited [9].

Fullerene $C_{60}$ linked to porphyrins show a higher capacity than porphyrins alone to form photoinduced processes [10]. Also, porphyrins connected to peripheral carbazoyl units represent efficient light-harvesting

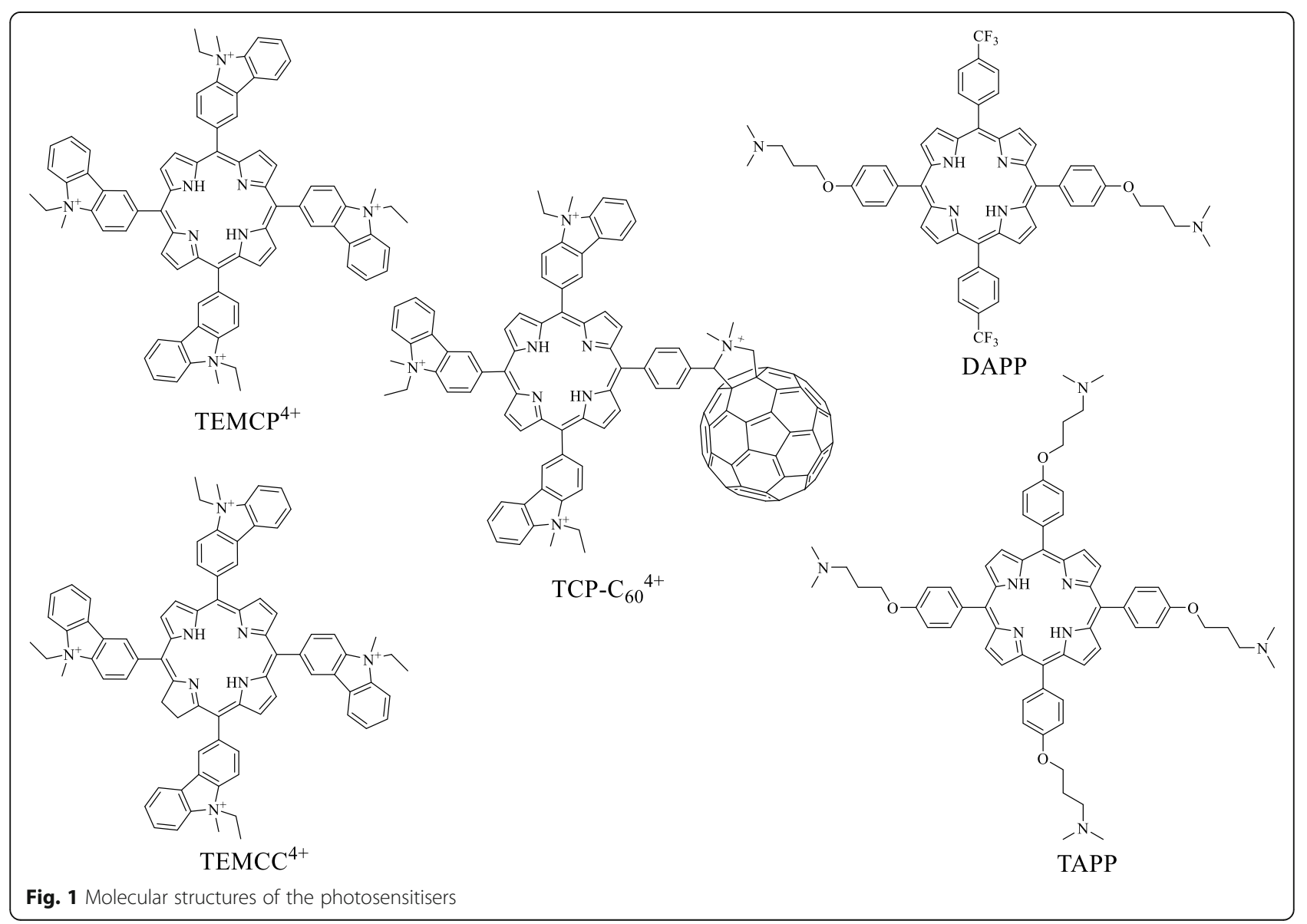


structures, where the carbazole groups can act as an antenna at lower wavelengths [11].

In this study, different porphyrin derivatives were evaluated as potential phototherapeutic agents (Fig. 1). Both the $\mathrm{TEMCP}^{4+}$ porphyrin and its analogue $\mathrm{TEMCC}^{4+}$ chlorine show an $\mathrm{A}_{4}$ symmetry, with identical substituents at the meso positions of the tetrapyrrolic macrocycle. Thus, cationic carbazoyl groups provide four intrinsic charges at the periphery of the macrocycle [12]. The TAPP derivative has also $\mathrm{A}_{4}$ symmetry, however, unlike the previous porphyrins, it is substituted at the meso positions by aminopropoxy groups. These substituents contain an aliphatic chain that culminates with an amine group, which allows greater mobility and the basic groups can acquire positive charges by protonation in the cellular microenvironment. This effect can improve the interaction between the molecule and the cells [13, 14]. The DAPP molecule has ABAB symmetry with two substituent groups -the aminopropoxy and the trifluoromethyl groups- in trans positions. The amino groups, precursors of cations, can provide two positive charges that, in combination with the highly lipophilic trifluoromethyl groups, generate an amphiphilic structure [15]. Finally, the TCP- $\mathrm{C}_{60}{ }^{4+}$ dyad is formed by a porphyrin unit covalently attached to the fullerene $\mathrm{C}_{60}$. The resulting porphyrin has three identical carbazoyl substituents with positive charges, which together with the pyrrolidine cationic group attached to fullerene $C_{60}$ provide four positive charges to the structure [16]. The synthesized compounds show the typical Soret absorption band 420-430 nm and four Q bands, between 515 and 650 $\mathrm{nm}$, characteristic of derivatives of substituted tetraphenyl porphyrins. Besides, porphyrins can be converted to the corresponding chlorin derivatives, which are efficient photosensitizsers [12].

This work aimed to evaluate the in vitro photoactivity of four meso-substituted compounds (three porphyrins and one analogous chlorin) and a porphyrin coupled to a fullerene structure. The cell line employed was the LM3 murine adenocarcinoma, and the more active PS was selected to be administered in vivo in a model of mice bearing the subcutaneously implanted adenocarcinoma for the analysis of biodistribution and tumour selectivity after systemic administration and skin localization after topical application.

\section{Methods}

\section{Chemicals}

The synthetic meso-porphyrin derivatives: 5,10,15,20-tetrakis[4-(3- $N, N$-dimethylaminopropoxy) phenyl]porphyrin (TAPP), 5,15-di (4-[3-N,N-dimethylaminopropoxy]phenyl)-10,20-di(4-trifluoromethylphenyl) porphyrin (DAPP), 5,10,15,20-tetrakis[3-( $N$-ethyl- $N$-methylcarbazoyl)] porphyrin $\quad\left(\mathrm{TEMCP}^{4+}\right), \quad$ 5,10,15,20-tetrakis[3-(N-ethyl- $N$ -
Table 1 Spectroscopic and photodynamic properties of the PSS in DMF

\begin{tabular}{lllllll}
\hline PS & $\boldsymbol{\varepsilon}^{\text {soret } \mathbf{a}}$ & $\boldsymbol{\lambda}_{\mathrm{abs}}{ }^{\mathbf{b}}$ & $\boldsymbol{\lambda}_{\mathbf{e m}}{ }^{\mathbf{c}}$ & $\boldsymbol{\Phi}_{\mathbf{F}}{ }^{\mathbf{d}}$ & $\boldsymbol{\Phi}_{\boldsymbol{\Delta}}{ }^{\mathbf{e}}$ & Reference \\
\hline TAPP & $1.64 \times 10^{5}$ & 422 & 660 & 0.15 & 0.53 & {$[17]$} \\
DAPP & $1.67 \times 10^{5}$ & 418 & 652 & 0.12 & 0.53 & {$[15]$} \\
TCP-C $_{60}{ }^{4+}$ & $2.49 \times 10^{5}$ & 432 & 664 & 0.005 & 0.02 & {$[16]$} \\
TEMCC $^{4+}$ & $1.24 \times 10^{5}$ & 432 & 656 & 0.23 & 0.49 & {$[12]$} \\
TEMCP $^{4+}$ & $2.80 \times 10^{5}$ & 431 & 664 & 0.13 & 0.40 & {$[12]$} \\
\hline
\end{tabular}

${ }^{\mathrm{a}}$ Molar absorption coefficient $\left(\mathrm{L} \mathrm{mol}^{-1} \mathrm{~cm}^{-1}\right.$ )

${ }^{b}$ Maximum absorption wavelength of the Soret band

'Maximum absorption wavelength of the emission band

${ }^{\mathrm{d}}$ Fluorescence quantum yield

e Quantum yield of singlet oxygen production

methylcarbazoyl)] chlorin $\left(\right.$ TEMCC $^{4+}$ ) were synthesized as previously reported $[12,15]$. The porphyrin- $\mathrm{C}_{60}$ dyad TCP- $\mathrm{C}_{60}{ }^{4+}$ was obtained as previously described [16] (Fig. 1 and Table 1). Further details on the synthesis of the compounds are shown in Supplementary material.

Stock solutions of PSs dissolved in DMSO were kept at $-70^{\circ} \mathrm{C}$ until use. They were dissolved in PBS at a maximum concentration of $0.1 \%$ DMSO for in vitro assays and in saline at $10 \%$ DMSO for in vivo studies.

MitoTracker ${ }^{\circ}$ Green, LysoTracker ${ }^{\circ}$ green and NBD-C6 ceramide were purchased from Thermo Fisher Scientific (Waltham, USA). MTT reagent was obtained from Sigma Aldrich Corp (St. Louis, USA).

All reagents and solvents were purchased from commercial suppliers and used without further purification.

\section{Cell lines}

LM3 cells derived from the murine mammary adenocarcinoma M3 [18] were kindly provided by the Instituto Roffo, Buenos Aires, Argentina. These cells were previously characterized genetically and morphologically, and have not been retested and authenticated in the present study. They were routinely grown in RPMI-1640 medium containing $2 \mathrm{mM} \mathrm{L}$-glutamine and phenol red, supplemented with $10 \%$ foetal bovine serum and incubated at $37^{\circ} \mathrm{C}$ in an atmosphere containing $5 \% \mathrm{CO}_{2}$. Cells were seeded at $7 \times 10^{4}$ cells $/ \mathrm{ml}$ and used $48 \mathrm{~h}$ after plating.

\section{PDT treatment}

Cells were incubated in serum-free medium containing the PS $(2.5 \mu \mathrm{M}$ and $5 \mu \mathrm{M})$ and $3 \mathrm{~h}$ later, irradiations were performed. After irradiation, the cells were gently washed 3-times with PBS and the cells were incubated in medium supplemented with serum for another $19 \mathrm{~h}$ and then tested for viability. Light dose 50 (LD50) was calculated as the dose in $\mathrm{mJ} / \mathrm{cm}^{2}$ necessary to induce $50 \%$ of cell death. 


\section{MTT viability assay}

Phototoxicity and cell viability were documented by the MTT assay [19]. This is a method based on the activity of mitochondrial dehydrogenases. Following appropriate treatments, MTT (3-[4,5-dimethylthiazol-2-yl]-2,5-diphenyltetrazoliumbromide) solution was added to each well in a concentration of $0.5 \mathrm{mg} / \mathrm{ml}$, and plates were incubated at $37^{\circ} \mathrm{C}$ for $1 \mathrm{~h}$. The resulting formazan crystals were dissolved by the addition of DMSO and absorbance was read at $560 \mathrm{~nm}$.

\section{Light source}

A bank of 2 fluorescent lamps (Osram L $18 \mathrm{~W} / 765$ ) was used. The spectrum of light was between 400 and 700 $\mathrm{nm}$ with the highest radiant power at $600 \mathrm{~nm}$. The 12 well plates containing the cells were located at a distance of $14 \mathrm{~cm}$ from the light source and were irradiated from below. The fluence rate was measured with a FieldMaster power meter and an LM3 HTP sensor (Coherent Inc., USA). We used fluences between 10 and $220 \mathrm{~mJ} /$ $\mathrm{cm}^{2}$ and the power density was $0.5 \mathrm{~mW} / \mathrm{cm}^{2}$.

\section{Cellular uptake of PSs}

The LM3 cells were exposed to different concentrations ranging from 0.15 to $5 \mu \mathrm{M}$ of PSs in medium without serum during 3 or $24 \mathrm{~h}$. The concentration ranges to perform intracellular PS accumulation profiles have been chosen based on MTT cytotoxicity assays (see Figure S1 and Table S1). After 3 consecutive washes with PBS, the PSs were extracted from the cells employing DMSO and afterwards, fluorescence was measured in a Perkin Elmer LS55 fluorimeter employing the maxima excitation and emission light wavelengths (Table 1). Standard solutions of PSs dissolved in DMSO were employed. The cellular uptake of the PSs per $10^{5}$ cells was determined from fluorescence calibration curves constructed by plotting the peak height of the PSs standard solutions. The calibration was linear within the employed range.

\section{Transport mechanism of TAPP into LM3 cells}

To assess passive transport contribution, LM3 cells were: i) exposed to cold TAPP $(1 \mu \mathrm{M}$ and $5 \mu \mathrm{M})$ in serum-free medium $90 \mathrm{~min}$ at $4{ }^{\circ} \mathrm{C}$; ii) exposed to pre-warmed TAPP in serum-free medium $90 \mathrm{~min}$ at $37^{\circ} \mathrm{C}$. After 3 consecutive washes with cold PBS, TAPP was extracted from the cells employing DMSO and quantified fluorimetrically as described in 2.6 employing TAPP standard solutions.

\section{Subcellular localization of TAPP}

LM3 cells were plated into coverslips and $48 \mathrm{~h}$ afterwards, incubated in the dark during 5,30 or $180 \mathrm{~min}$ at $37^{\circ} \mathrm{C}$ with $5 \mu \mathrm{M}$ TAPP and red fluorescence was microscopically documented. In addition, cells were exposed
$180 \mathrm{~min}$ to $5 \mu \mathrm{M}$ TAPP and then rinsed and incubated further $30 \mathrm{~min}$ with organelles specific fluorescent probes. To identify the Golgi apparatus, mitochondria and lysosomes, cells were labelled with $5 \mu \mathrm{M}$ NBD-C6 ceramide, $0.1 \mu \mathrm{M}$ MitoTracker ${ }^{\circ}$ Green and LysoTracker ${ }^{\circ}$ Green, respectively. Coverslips were mounted onto a glass microscope slide with $D A B C O-\mathrm{PBS}$ mounting medium. Microscopic observation and photography were performed in an Olympus photomicroscope BX51.

Colocalization was quantified with Pearson's correlation coefficient (PCC) employing Fiji image analysis software using the JaCOP plugin. Absolute PCC values of 1-0.7 indicate a relatively strong correlation, 0.69 0.36 a moderate correlation, $0.35-0.2$ a weak correlation, and $<0.2$ the absence of a correlation [20].

Fiji software [21] was also employed to quantify fluorescence intensity for the TAPP red channel. To measure fluorescence intensity of the images, RGB micrographs were splitted into grayscale images of the 3 channels. For TAPP red quantification, the green and blue channels were discarded. In order not to alter pixel values, the image was duplicated before processing. To accurately measure intensity values inside cell, the cell area was selected using the thresholding tools available, and when the region was properly bounded, it was saved as the region of interest using the ROI manager tool. This region fits accurately with the cellular area. Using the measure tool, both the whole area and the fluorescence of the selected region were quantified. Then, the fluorescence value inside the cell area was divided by the cell area.

\section{Animals}

Male BALB/c mice 12 weeks old, weighing 20-25 g were used. The mice were purchased from the IMPAM Animal House, School of Medicine, University of Buenos Aires and housed in the Laboratory Animal Resources facility at the CIPYP during the experimental procedures. Genotyping of mice was routinely carried out at the IMPAM Animal House. Healthy conventional mice were employed. They were provided with food (Purina 3, Molinos Río de la Plata, Argentina) and water ad libitum. Tumour inoculations were carried out after a period of acclimatization of 7 days. A suspension of $1.6 \times 10^{5}$ cells of the LM3 cell line was subcutaneously injected on the left flank of mice. Animals were used at approximately day 20 after implantation. Tumor incidence was observed every two to 3 days for the 20-days period. Animals bearing tumours of the same uniform size were employed ( $1 \mathrm{~cm}$ diameter), and were divided into treatment and control groups by simple randomization. The sample size was calculated with $G^{*}$ power 3.1 software. Animals protocols were approved by the Argentinean Committee (CICUAL, School of 
Medicine, University of Buenos Aires) in full accord with the UK Guidelines for the Welfare of Animals in Experimental Neoplasia [22] and adhering to the ARRIVE guidelines.

\section{TAPP administration to mice}

For topical and intraperitoneal administration, TAPP was dissolved in saline solution containing 10\% DMSO immediately before use.

\section{Topical administration}

For topical application, $200 \mu \mathrm{l}$ of the TAPP solution $(100 \mu \mathrm{g}$ TAPP) was applied on the tumour, after shaving the hair and rubbing with a paintbrush for 5 min ( 3 mice per experiment, 2 independent experiments). Fluorescence spectroscopy was performed on the skin over the tumour (SOT), and on the normal skin of the opposite flank, named 'distant skin'. Skin sections were taken for fluorescence distribution imaging. Control animals (3 mice per experiment, 2 independent experiments) were topically treated with the vehicle. One week after TAPP treatment, skin biopsies of animals revealed no signs of photodamage.

In vivo fluorescence spectroscopy In vivo fluorescence measurements were carried out for studying the kinetics of TAPP skin accumulation after topical application. A bifurcated fibre-optic probe was coupled to a PerkinElmer LS55 spectrofluorimeter, and fluorescence from the skin was detected at the probe tip. Fluorescence intensity was measured as a function of time and expressed in arbitrary units at an excitation wavelength of $420 \mathrm{~nm}$ and emission of $660 \mathrm{~nm}$. In addition, fluorescence emission spectra were recorded to verify that the fluorescence signal corresponded to TAPP.

Fluorescence imaging of skin distribution following topical application of TAPP SOT + tumour samples topically applied with TAPP, were frozen and $15-\mathrm{mm}$ thick cryosections were prepared and handled under subdued lighting conditions. Microscopic observation was performed (Olympus BX51 microscope) using excitation at $545 \mathrm{~nm}$ using a bandpass filter and images were recorded using a Q-color 5 camera. After fluorescence observation, sections were stained with hematoxylin and eosin to identify structures of fluorescence localization.

\section{Systemic administration of TAPP}

For systemic administration, $150 \mu \mathrm{l}(4 \mathrm{mg} / \mathrm{kg}$ mice $)$ of TAPP was intraperitoneally injected to mice. Mice were sacrificed after 3, 24, 48 or $72 \mathrm{~h}$ after systemic administration ( 3 mice per time point). After determining the appropriate time point, the experiment was repeated twice (3 mice for TAPP treatment, 3 mice for controls).
Before the sacrifice, mice were injected with heparin and afterwards, they were perfused with of sterile saline. Animals were euthanized with carbon dioxide. The organs samples were homogenized in DMSO, centrifuged for $30 \mathrm{~min}$ at $3000 \mathrm{~g}$, and the supernatants were employed for the fluorimetric quantification of TAPP. A Perkin Elmer LS55 spectrofluorimeter (Buckinghamshire, UK) was used, employing excitation/emission wavelengths of 425/660 nm.

Control animals were injected with the vehicle. Mice were always kept in the dark until sacrifice.

Mice were carefully monitored daily. Under the aboveexplained conditions, the animals treated with TAPP did not show any visible signs of toxicity or significant change in body weight or food and water intake as compared to the controls. The biochemical indexes of liver and kidney function, as well as the blood counts, were not different from the controls (see supplementary material Tables S1, S2 and S3).

\section{Statistical treatment}

The values in the figures and tables are expressed as means \pm standard deviations of the mean. A two-tailed Student's $t$-test with a preliminary normality test, was used to determine statistical significance between means. $P$ values $<0.05$ were considered significant. Simple linear

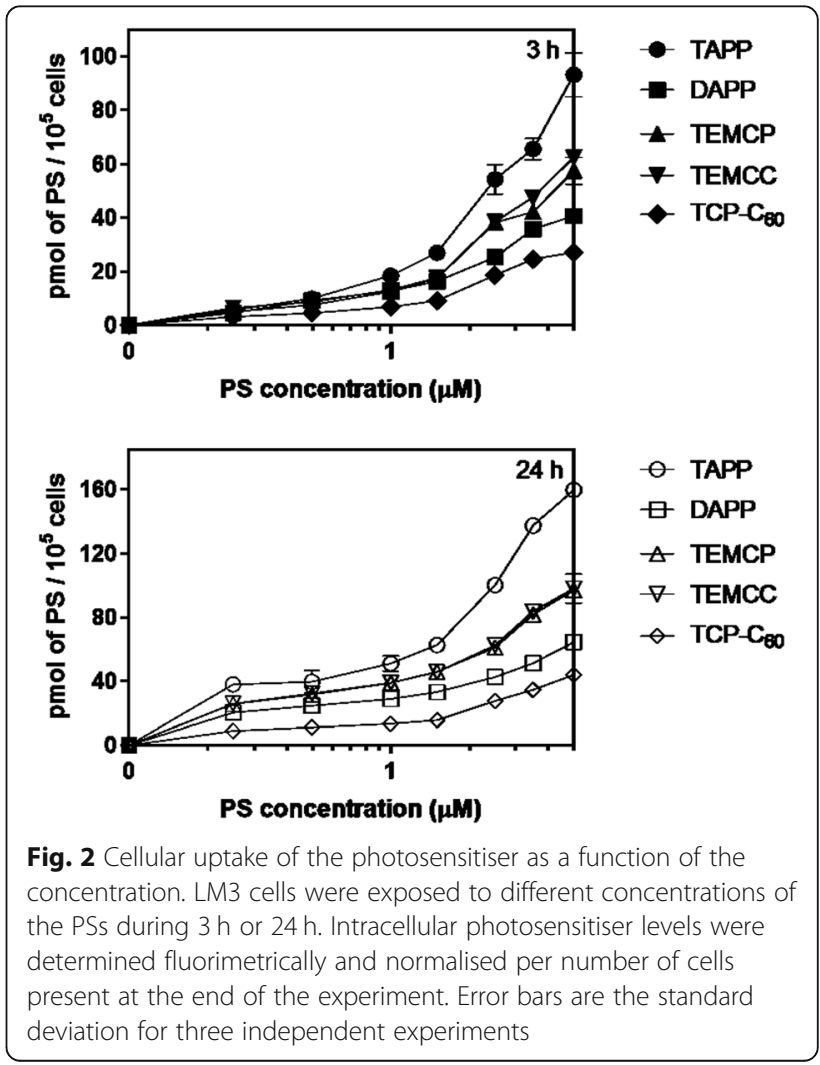


regression analysis was performed using the GraphPad Software (version 6.0; GraphPad Prism).

\section{Results}

\section{Cellular incorporation of PSs}

LM3 cells were exposed to increasing non-dark toxic concentrations of the PSs during $3 \mathrm{~h}$ or $24 \mathrm{~h}$ (Fig. 2). Intracellular accumulated PSs increase linearly as a function of the concentration added at both periods (linear regression analysis, TAPP $r^{2}=0.9849$; TEMCC $^{4+} \mathrm{r}^{2}=0.9812$; TEMCP $^{4+}$ $r^{2}=0.9706 ;$ DAPP $r^{2}=0.9634 ;$ TCP-C ${ }_{60}{ }^{4+} r^{2}=0.9547$ ) for a $3 \mathrm{~h}$ period within the concentration range studied. This pattern is similar for all the PSs, with different slopes for each curve of incorporated PS vs concentration.

Uptake efficiency can be divided into 3 groups. For example, focusing in the $3 \mathrm{~h}-5 \mu \mathrm{M}$ profiles: a) TAPP, which is taken up by the cells with maximal efficiency (values higher than $60 \mathrm{pmol}$ of $\mathrm{PS} / 10^{5}$ cells); b) TEMC $\mathrm{C}^{4+}$, $\mathrm{TEMCP}^{4+}$ and DAPP, being incorporated with medium efficacy ( 25 to $60 \mathrm{pmol}$ of PS/ $10^{5}$ cells; and c) TCP- $\mathrm{C}_{60}{ }^{4+}$, which is poorly incorporated into the cells (less than $25 \mathrm{pmol}$ of PS $/ 10^{5}$ cells).

At $24 \mathrm{~h}$, the values of incorporated PSs are higher than the ones obtained at $3 \mathrm{~h}$, showing increases of 1.5 to 1.7 fold at the highest concentration employed.
In vitro photodynamic therapy

PDT mediated by the action of the different PSs was studied as a function of the increasing light dose (Fig. 3). The conditions evaluated were 3 and $24 \mathrm{~h}$ incubation periods, and 2.5 and $5 \mu \mathrm{M}$ concentrations. $\mathrm{LD}_{50} \mathrm{~s}$ taken from Fig. 3 are summarised in Table 2 to help the analysis.

In line with the intracellular amount of incorporated PS, at $3 \mathrm{~h}$ of incubation, TAPP turned out to be the best PS, inducing $\mathrm{LD}_{50} \mathrm{~S}$ of 35.7 and $22.9 \mathrm{~mJ} / \mathrm{cm}^{2}$ employing $2.5 \mu \mathrm{M}$ y $5 \mu \mathrm{M}$ respectively. $\mathrm{TEMCC}^{4+}$, $\mathrm{TEMCP}^{4+}$ and DAPP exert medium photosensitisation levels with $\mathrm{LD}_{50} \mathrm{~s}$ between 100 and $136 \mathrm{~mJ} / \mathrm{cm}^{2}$ at $2.5 \mu \mathrm{M}$, and a slightly higher photoactivity $\left(89\right.$ to $100 \mathrm{~mJ} / \mathrm{cm}^{2}$ ) at the highest concentration. TCP- $\mathrm{C}_{60}{ }^{4+}$ was the least photoactive compound $\left(\mathrm{LD}_{50}>220 \mathrm{~mJ} / \mathrm{cm}^{2}\right)$ at both concentrations.

Employing $24 \mathrm{~h}$ time exposures, $\mathrm{LD}_{50} \mathrm{~S}$ are nor directly correlated with the intracellularly accumulated PS (see Fig. 2). As compared to $3 \mathrm{~h}$, TAPP was equally photoactive at $2.5 \mu \mathrm{M}$ and less photoactive at $5 \mu \mathrm{M}$, whereas $\mathrm{TEMCC}^{4+}$, $\mathrm{TEMCP}^{4+}$ and DAPP were 10 to $20 \%$ more active, and $\mathrm{TCP}-\mathrm{C}_{60}{ }^{4+}$ increased remarkably its photosensitising efficacy, inducing an $\mathrm{LD}_{50}$ of $125 \mathrm{~mJ} / \mathrm{cm}^{2}$. Considering the above-mentioned results, TAPP was

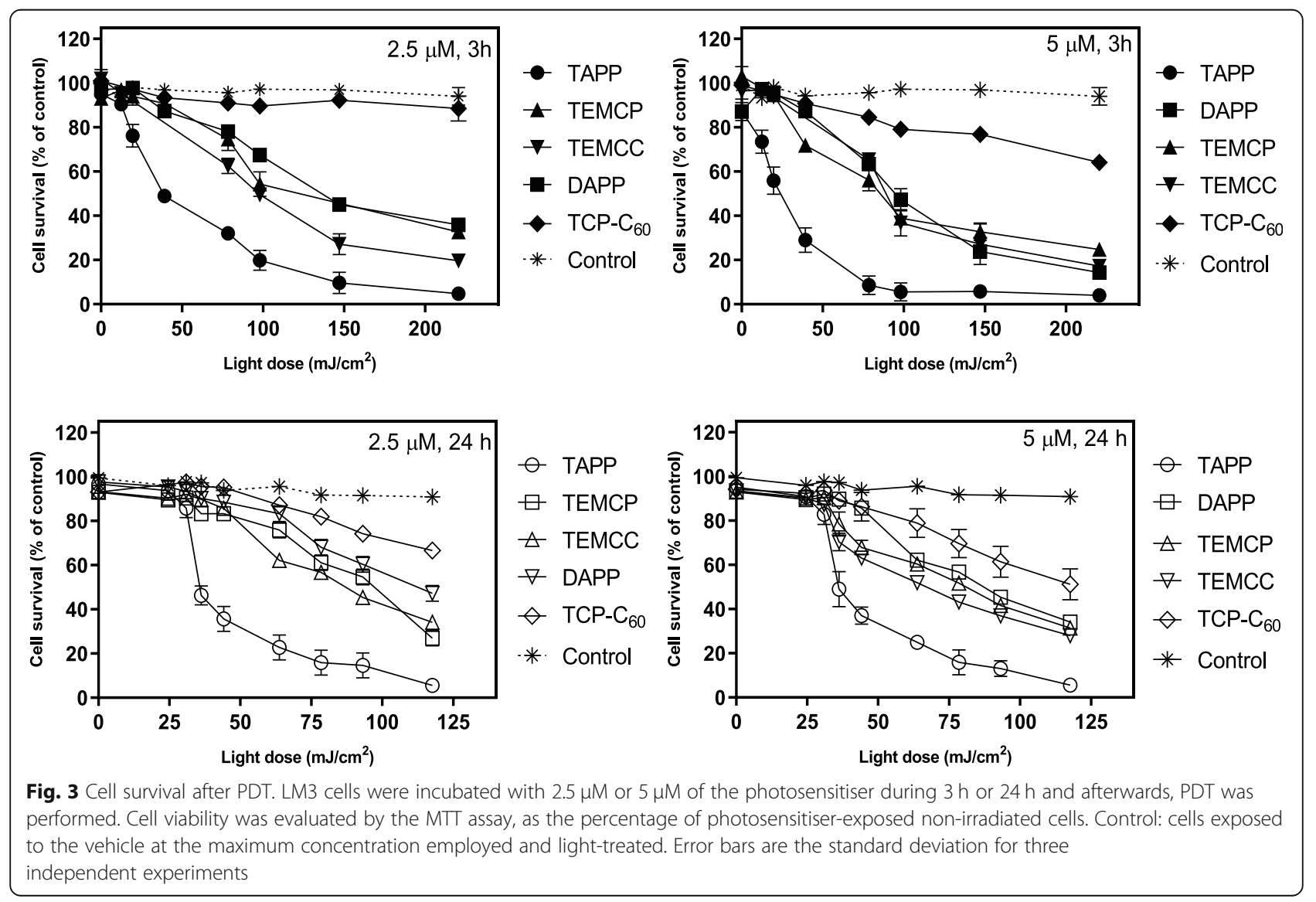


Table $2 L_{50} S$ of PDT mediated by the different PSs in LM3 cells, calculated from Fig. 2 values

\begin{tabular}{|c|c|c|c|c|c|c|}
\hline \multicolumn{7}{|c|}{$\mathrm{LD}_{50}\left(\mathrm{~mJ} / \mathrm{cm}^{2}\right)$} \\
\hline $\begin{array}{l}\text { Incubation } \\
\text { time }\end{array}$ & Concentration & TAPP & $\begin{array}{l}\text { TEMC } \\
\mathrm{C}^{4+}\end{array}$ & TEMCP $^{4+}$ & DAPP & $\begin{array}{l}\text { TCP- } \\
\mathrm{C}_{60}{ }^{4}\end{array}$ \\
\hline \multirow[t]{2}{*}{$3 \mathrm{~h}$} & $2.5 \mu \mathrm{M}$ & 35.7 & 100.6 & 101.2 & 136.2 & $\begin{array}{l}> \\
220.0\end{array}$ \\
\hline & $5 \mu \mathrm{M}$ & 22.9 & 88.9 & 92.0 & 99.8 & $\begin{array}{l}> \\
220.0\end{array}$ \\
\hline \multirow[t]{2}{*}{$24 \mathrm{~h}$} & $2.5 \mu \mathrm{M}$ & 34.6 & 87.4 & 97.2 & 112.5 & $\begin{array}{l}> \\
220.0\end{array}$ \\
\hline & $5 \mu \mathrm{M}$ & 35.8 & 66.7 & 80.4 & 87.4 & 125.0 \\
\hline
\end{tabular}

considered the best photosensitizing molecule and was further studied. Figure S4 confirms that the damage observed after TAPP-PDT is due to reactive oxygen species generation.

\section{Transport mechanism of TAPP into LM3 cells}

Figure 4 shows the contribution of passive transport of TAPP, inferred from its intracellular uptake and its differential photodynamic effect at $4{ }^{\circ} \mathrm{C}$ and $37^{\circ} \mathrm{C}$. An active transport system would be completely blocked by lowering the temperature to $4{ }^{\circ} \mathrm{C}$, whereas the involvement of passive transport would imply uptake at low temperature [23]. Figure 4a shows that TAPP cellular uptake is impaired at $4{ }^{\circ} \mathrm{C}$ at about 60 to $70 \%$ as compared to the $37^{\circ} \mathrm{C}$ conditions. In line with this result, $\mathrm{LD}_{50}$ increases from $68.0 \mathrm{~mJ} / \mathrm{cm}^{2}$ to $202.5 \mathrm{~mJ} / \mathrm{cm}^{2}$ by lowering the temperature, that is a 3 -fold decline on the therapeutic efficacy (Fig. 4b).

\section{Fluorescence microscopy of cells exposed to TAPP}

Fluorescence microscopy shows the time-dependence of TAPP cellular uptake at short incubation times. Intracellular TAPP fluorescence is observed at the 3 the time points analysed (Fig. 5a). After $5 \mathrm{~min}$ incubation, a diffuse cytoplasmic pattern can be distinguished, whereas, at $30 \mathrm{~min}$ and $3 \mathrm{~h}$, a punctuate pattern becomes evidenced, suggesting confinement to subcellular organelles. The quantification of red fluorescence indicates that equal fluorescence values are attained at the 3 time points (data not depicted).

In Fig. 5b we studied the colocalization of TAPP after $3 \mathrm{~h}$ exposure with organelle-specific probes. PCC values quantifying the colocalization of the organelles fluorescent marker and TAPP are as follows: mitochondria: $0.36 \pm 0.08$, lysosomes: $0.36 \pm 0.05$ and Golgi apparatus: $0.68 \pm 0.03$. The results suggest that TAPP mainly localizes in the Golgi apparatus and at a lesser extent in mitochondria and lysosomes. In addition, a diffuse cytoplasmatic signal, not ascribable to organelles can be distinguished.

\section{In vivo studies}

\section{TAPP topical application}

Figure 6 shows TAPP accumulation in SOT and distant skin after topical application on LM3 tumours. SOT: distant skin fluorescence ratio is around 7 between $30 \mathrm{~min}$ and $6 \mathrm{~h}$ after application and around 4 at $36 \mathrm{~h}$, showing TAPP retention in the application site.

To analyse the penetration depth of TAPP through the skin, its fluorescence localization was observed microscopically in SOT after topical application of TAPP. TAPP is mainly retained in the epidermis but does not further diffuse to the dermis, subcutaneous adipose tissue or the subcutaneous-located tumour. In hair follicles and sebaceous glands, TAPP fluorescence is also observed. The $H \& E$ staining reveals the absence of damage to the skin induced by TAPP application in mice kept in the dark.

\section{Systemic TAPP biodistribution}

A non-toxic amount of TAPP $(4 \mathrm{mg} / \mathrm{kg})$ was injected intraperitoneally to tumour-bearing mice. Three, 24,48 or
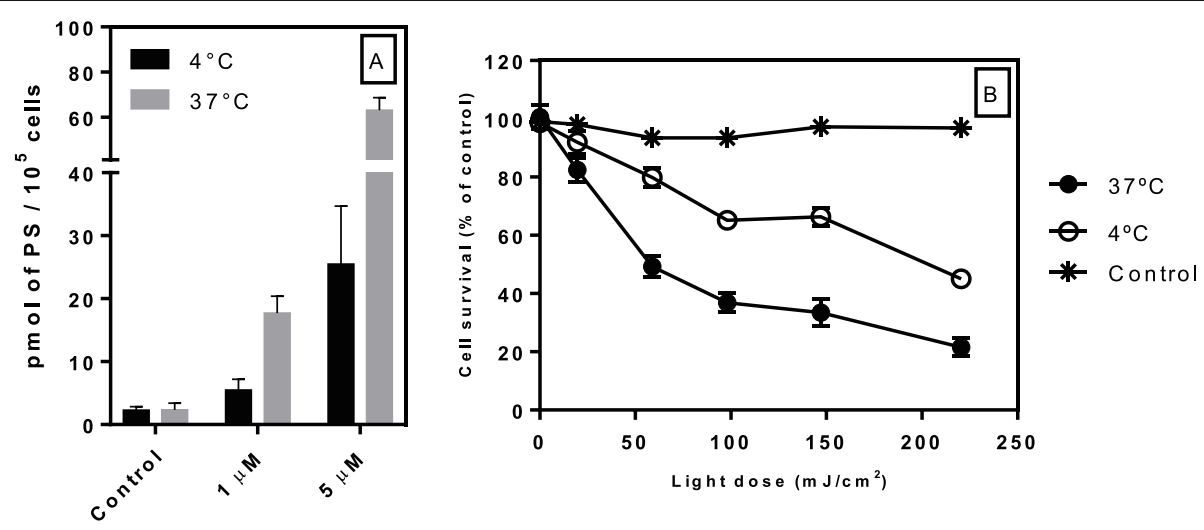

Fig. 4 The transport mechanism of TAPP into LM3 cells. Cell uptake of TAPP at $1 \mu \mathrm{M}$ and $5 \mu \mathrm{M}$ at $4^{\circ}$ and $37^{\circ} \mathrm{C}$ during 90 min (a). Photodamage induced by the incorporated $5 \mu \mathrm{M}$ TAPP for $90 \mathrm{~min}$ at $4^{\circ}$ and $37^{\circ} \mathrm{C}$ and illuminated at different light doses (b). Control: cells exposed to the vehicle and light-treated. Error bars are the standard deviation for three independent experiments 


\section{TAPP exposure time}

\section{Colocalization}
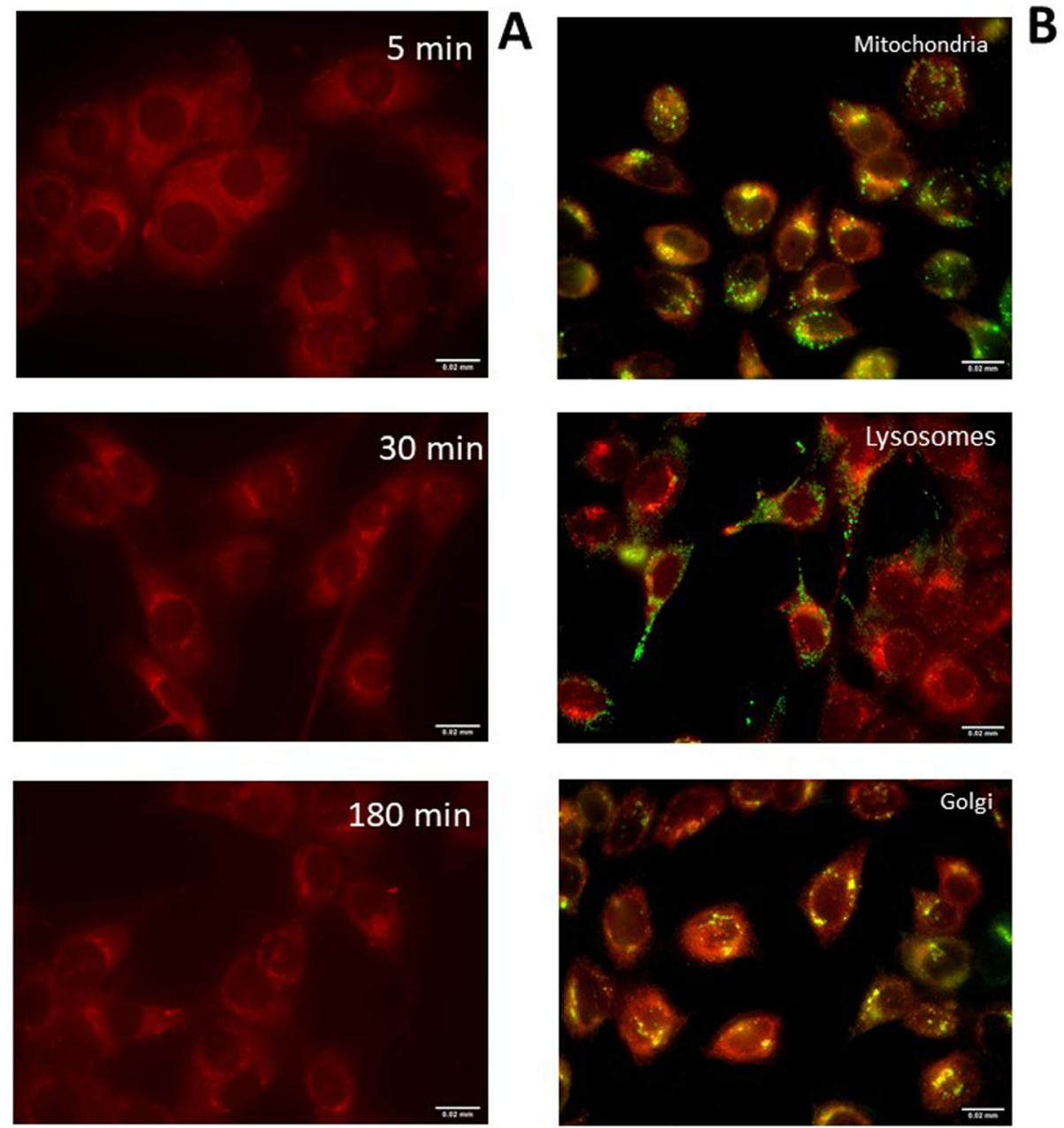

Fig. 5 Intracellular TAPP fluorescence and colocalization. LM3 cells were exposed to $5 \mu$ M TAPP for 5 min, 30 min and 180 min, and red fluorescence was visualized by fluorescence microscopy (a). Cells exposed to TAPP for $180 \mathrm{~min}$ (red fluorescence) were then incubated with Lysotracker Green ${ }^{\oplus}$, Mitotracker Green ${ }^{\oplus}$, or NBD C6-Ceramide (green fluorescence) (b). Magnification 100X. These micrographs were representative of those obtained from three independent experiments

$72 \mathrm{~h}$ after TAPP systemic administration, the amount of TAPP was quantified in the tumour and the organs. Maximal accumulation of TAPP was observed in all the tissues at $24 \mathrm{~h}$ post-administration. However, even at $72 \mathrm{~h}$ afterwards, fluorescence was still present in tissues such as tumour and SOT (data not shown).

Figure 7 depicts the accumulation of TAPP obtained at $24 \mathrm{~h}$ after i.p. injection. Basal autofluorescence values varied among tissues, and for that reason, autofluorescence of control tissues is also depicted. The amount of TAPP is maximal in tumour tissue. Besides, SOT accumulates significantly more TAPP than normal skin ( $p=0.004$, Student's $t$-test). These values lead to a high selectivity index of 13 for tumour: SOT ratio and 26 for tumour: normal skin.
Besides, elevated TAPP concentrations were registered in the lung and intestine. On the other hand, lower values of TAPP were found in the rest of the organs such as distant skin, kidney, liver and spleen. It is quite important to remark that the brain did not accumulate TAPP at all. Plasmatic TAPP was detected up to $72 \mathrm{~h}$ after administration (data not shown).

\section{Discussion}

In the present work, we have found that TAPP, DAPP, TEMCC $^{4+}$ and TEMCP $^{4+}$ exhibit high photoactivity against LM3 mammary carcinoma cells. Among them, TAPP was the most active molecule, and its biodistribution was tested after topical application and systemic administration. 

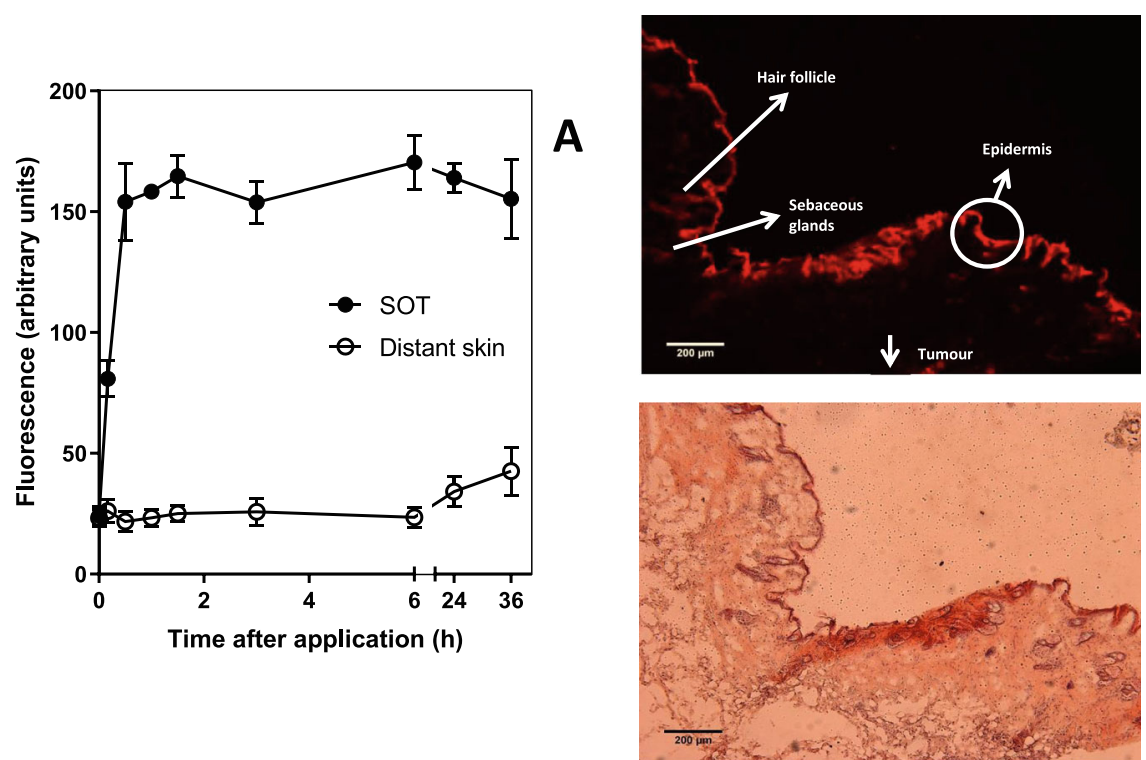

Fig. 6 TAPP accumulation in the skin over the tumour (SOT) and distant skin after topical application of TAPP on the SOT of LM3 bearing mice. TAPP was applied topically on SOT (100 $\mathrm{\mu g}$ TAPP in saline containing 10\% DMSO). Animals were kept in the dark. At different times after application, TAPP fluorescence was monitored. Determinations were made on SOT and over a distant skin area. The average of three mice per treatment in 2 independent experiments is shown (a). Fluorescence and hematoxylin and eosin-stained images of SOT after $24 \mathrm{~h}$ of TAPP application. Magnification 10X objective (b)

Previous experiments showed that $\mathrm{TEMCC}^{4+}$ was a highly effective agent to photo-induce the hemolysis of human red blood cells, whereas TEMCP ${ }^{4+}$ induced hemolysis at a lower extent due to haemoglobin absorption [12].

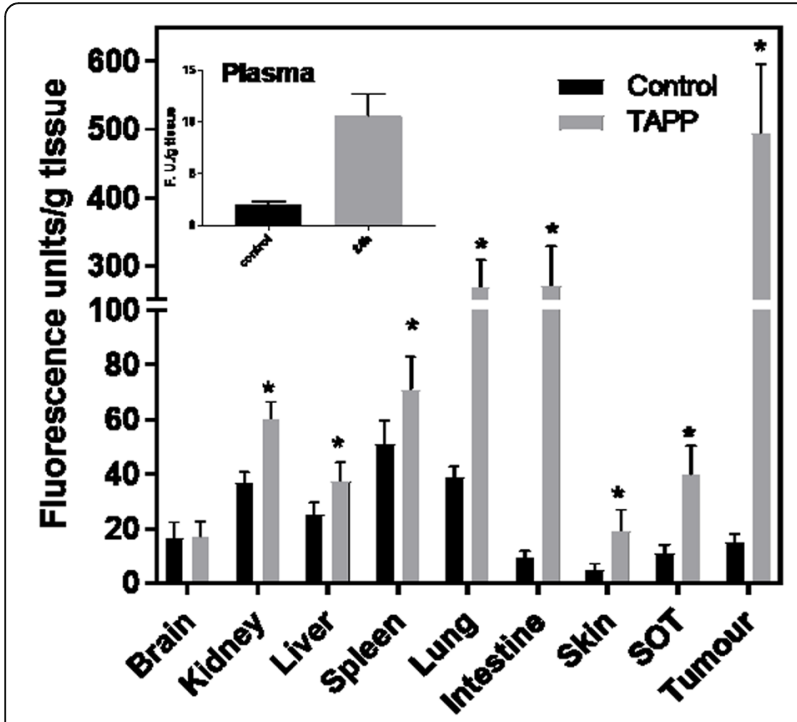

Fig. 7 Biodistribution of TAPP after systemic administration. TAPP was intraperitoneally administrated to LM3 tumour bearing mice (4 $\mathrm{mg} / \mathrm{kg}$ ) and after $24 \mathrm{~h}$ of administration, TAPP was extracted from tissues and quantified. The results are expressed as fluorescence units/g tissue (means \pm SD). The average of three data in 2 independent experiments is shown. ${ }^{*} P<0.01$ as compared to the control injected with the vehicle (two-tailed Student's $t$-test)
Furthermore, TAPP demonstrated to be an efficient generator of singlet oxygen in the presence of oxidizable substrates, such as 9,10-dimetylanthracene and L-tryptophan in biomimetic media [17]. On the other hand, porphyrinfullerene $\mathrm{C}_{60}$ dyads with high ability to form photoinduced charge-separated state were evaluated as PS with potential application in the photoinactivation of S. aureus [16].

Cellular uptake of the PSs employed in the present work suggests that all the PSs assayed are incorporated linearly as a function of the added concentration, suggesting a major involvement of passive transport in the uptake of the PSs. The different slopes of the curves of incorporated PS as a function of the concentration suggest different incorporation rates.

Our results suggest that at $3 \mathrm{~h}$ of exposure, the amount of intracellular PS correlates fairly with the photodamage degree. However, even when at $24 \mathrm{~h}$ the intracellular accumulated PS is higher than at $3 \mathrm{~h}$, a direct correlation with the photodamage degree was not always observed. Whereas TEMCC ${ }^{4+}$, TEMCP $^{4+}$ and DAPP were 10 to $20 \%$ more photoactive at $24 \mathrm{~h}$ as compared to $3 \mathrm{~h}$, TAPP employed at $5 \mu \mathrm{M}$ concentration, was less photoactive at longer incubation times and TCP- $\mathrm{C}_{60}{ }^{4+}$ was the only PS that increased remarkably its efficiency of photosensitisation.

The different behaviour for each PS suggests that depending on the molecule and the intracellular concentration, the photoactivity is variable. The different substituents, as well as the degree of axial symmetry, 
have been suggested to contribute to the cellular uptake. The positive charges located in the molecule periphery, increased the amphipathic character of the PS, thus contributing to the interaction with cell membranes [7]. In the present study, TAPP is taken up by the cells at a higher rate than the rest of the PSs.

TAPP bears four mobile dimetilaminopropyl groups as precursors of cationic centres. Considering the $\mathrm{pK}_{\mathrm{a}}$ values of these substituents [24], a high percentage of the amine groups can acquire positive charges by protonation in water, favouring a better interaction with cells. In the cases of $\mathrm{TEMCP}^{4+}$ and $\mathrm{TEMCC}^{4+}$, although these porphyrin derivatives have four carbazoyl substituents with intrinsic cationic groups, the cationic groups are in a rigid macrocycle structure and less exposed to interact with cells. On the other hand, DAPP has only two amine groups, while the dyad $\mathrm{TCP}-\mathrm{C}_{60}{ }^{4+}$ contains four rigid charges and a bulky and highly lipophilic $\mathrm{C}_{60}$ group that decreases an effective interaction with the cells.

Besides, TAPP, DAPP, and TEMCC4+ have quantum yields of singlet oxygen production in the range of 0.49 to 0.53 , and TEMCP4+ has a slightly lower (0.40) quantum yield.

In terms of efficiency of photosensitization, it is worth to note that after $3 \mathrm{~h}$ of incubation, TAPP induced on LM3 cells an $\mathrm{LD}_{50} \mathrm{~s}$ of 35.7 and $22.9 \mathrm{~mJ} / \mathrm{cm}^{2}$ employing $2.5 \mu \mathrm{M}$ and $5 \mu \mathrm{M}$ concentrations, respectively. On the other hand, after $3 \mathrm{~h}$ exposure of the same cell line to the already marketed pro-photosensitizer 5aminolevulinic acid $(25 \mu \mathrm{M})$, it was previously reported by us that a light dose of $150 \mathrm{~mJ} / \mathrm{cm}^{2}$ (same light array) was required to induce the same level of cell killing [25]. This comparison suggests that the porphyrin TAPP is a promising PS.

The impaired action of $5 \mu \mathrm{M}$ TAPP at longer incubation times may be ascribed to saturation of the intracellular targets and, at higher concentrations, TAPP molecules could be aggregated, thus inducing a diminished activity. On the other hand, the higher action of the porphyrin coupled to the fullerene at long incubation periods may suggest better solubilization as monomers since this structure is prone to form aggregates in aqueous media, increasing the photodynamic activity. Besides, the action of proteases may be needed to act at long times of exposure to release the porphyrin from the $\mathrm{C}_{60}$ structure.

TCP- $\mathrm{C}_{60}{ }^{4+}$ is the least photoactive porphyrin, and this is correlated with a poor cellular uptake and, in addition to a low singlet oxygen quantum yield in polar media, which is 6-fold lower as compared to the other PSs. The poorer uptake of the molecule is probably due to the presence of a voluminous group and the scarce endocytic ability of the LM3 cells. In addition, as suggested previously [26], drugs coupled to fullerenes can significantly differ from the free drug in terms of cellular uptake and subcellular distribution.

A major contribution of passive transport in the cellular uptake of TAPP is line with its reported Log P of 1.67 [27]. Besides, Golgi major localization, as well as moderate localization in lysosomes and mitochondria and diffuse cytoplasmatic pattern, is observed at $3 \mathrm{~h}$ of TAPP exposure. Lysosomes and the trans-Golgi network usually have an acidic lumen with $\mathrm{pH}$ of approximately 5 and 6.5 , respectively, so that weak bases are likely to be charged at a higher extent [28], thus exhibiting more marked fluorescence. The subcellular location of a PS is known to have a strong influence on the cell death response to photoinactivation .

Among the 5 analysed molecules, TAPP was the most photoactive in the cell line employed, and thus, was the chosen PS to be employed in a tumour bearing mice model. After topical application, TAPP was almost completely retained in the stratum corneum of the skin, without diffusion to the deeper layers of the skin. However, some fluorescence can be distinguished in the hair follicles and sebaceous glands suggesting a contribution of the transfollicular route of drug delivery. Specific localization of TAPP in the stratum corneum suggests the use of TAPP-PDT for the treatment of actinic keratosis.

As well, recent reports demonstrated that the transepidermal route, hair follicles, and sebaceous glands significantly contribute to topical or transdermal delivery. Malignant cutaneous adnexal neoplasms form a group of rare, typically low-grade-malignancy carcinomas with follicular, sebaceous, apocrine, or eccrine differentiation or a combination of the first 3 subtypes, and PDT has already been performed in some of these diseases $[29,30]$. The presence of TAPP in hair follicles and sebaceous glands, suggests the possibility to use this molecule in the photodynamic treatment of skin adnexal neoplasms.

Systemic administration of TAPP produce accumulation of high quantities of TAPP in tumour and SOT (tumour invaded skin), showing a high tumour: normal skin ratio of 31.4. It is also interesting to note the lack of accumulation of TAPP in brain tissue, evidencing that the molecule does not passage through the bloodbrain barrier. Besides, high intestine and lung TAPP values suggest the possibility of employing TAPPPDT for the treatment of colon and lung cancer, since both organs are easily accessible by optic fibres if further studies confirm the accumulation of TAPP in tumours of that origin.

The key conclusion of this study was that TAPP was the PS that showed the best performance in vitro. Upon topical application to tumour bearing mice, TAPP was retained in the stratum corneum and adnexal glands, 
having a potentiality in the treatment of superficial malignancies or pre-malignancies such as actinic keratosis and skin adnexal neoplasms after topical application. After systemic administration, it is highly selective for tumour tissue, thus having promising uses in PDT treatment of non-dermatologic conditions.

\section{Abbreviations}

DAPP: 5,15-di (4-[3-N,N-dimethylaminopropoxy]phenyl)-10,20-di (4trifluoromethylphenyl) porphyrin; MTT: 3-[4,5-dimethylthiazol-2-yl]-2,5diphenyltetrazoliumbromide); PCC: Pearson's correlation coefficient; PDT: Photodynamic therapy; PS: Photosensitizer; SOT: Skin over the tumour; TAPP: 5,10,15,20-tetrakis[4-(3-N,N-dimethylaminopropoxy) phenyl]porphyrin; TEMCC $^{4+}:$ 5,10,15,20-tetrakis[3-(N-ethyl-N-methylcarbazoyl)] chlorin $\left(\right.$ TEMCC $^{4+}$ ); TEMCP $^{4+}:$ 5,10,15,20-tetrakis[3-(N-ethyl-N-methylcarbazoyl)] porphyrin

\section{Supplementary Information}

The online version contains supplementary material available at https://doi. org/10.1186/s12885-021-08286-6.

Additional file 1.

\section{Acknowledgements}

We acknowledge Miss Vanina Ripoll and Mrs. Victoria Castillo for technical support.

\section{Declaration of interests \\ None.}

\section{Authors' contributions}

PV: Investigation, Methodology; MBB, DF: Chemical synthesis, Methodology; DS, GC: Methodology, analysis; GDV: Supervision, Writing - review \& editing; $L M$ : Formal analysis, review and editing; ED: Chemical synthesis, Funding acquisition, Manuscript writing; AC: Conceptualization, Funding acquisition, writing- original draft. All authors have read and approved the manuscript.

\section{Funding}

This research was supported by the Agencia Nacional de Promoción Cientifica y Tecnológica, ANPCyT (PICT 2014-0727 and PICT 2016-0667), and CONICET (PIP 2014 number $11220130100237 C O$ and PIP 2015 number 11220150100197 CO). The funding did not affect the design of the study, collection, analysis or interpretation of data or preparation of the manuscript.

\section{Availability of data and materials}

All of the data supporting our findings can be found in the main paper and Supplementary material. Data are however available from the authors upon reasonable request.

\section{Declarations}

Ethics approval and consent to participate

Animal protocols were approved by the Argentinean Committee (CICUAL, School of Medicine, University of Buenos Aires).

\section{Consent for publication}

Not applicable.

\section{Competing interests}

None.

\section{Author details}

${ }^{1}$ Centro de Investigaciones sobre Porfirinas y Porfirias (CIPYP), CONICET and Hospital de Clínicas Gral. José de San Martín, Universidad de Buenos Aires, Córdoba 2351 1er subsuelo, CP1120AAF Ciudad de Buenos Aires, Argentina ${ }^{2}$ IDAS-CONICET, Departamento de Química, FCEFQYN, Universidad Nacional de Río Cuarto, Río Cuarto, Córdoba, Argentina.
Received: 9 March 2021 Accepted: 4 May 2021

Published online: 13 May 2021

\section{References}

1. Weishaupt KR, Gomer CJDT. Identification of singlet oxygen as the cytotoxic agent in photoinactivation of a murine tumor. Cancer Res. 1976;36(7 PT 1): 2326-9.

2. Dougherty TJ, Gomer CJ, Henderson BW, Jori G, Kessel D, Korbelik M, et al. Photodynamic therapy. J Natl Cancer Inst. 1998;90(12):889-905. https://doi. org/10.1093/jnci/90.12.889

3. Tampa M, Sarbu Ml, Matei C, Mitran Cl, Mitran Ml, Caruntu C, et al. Photodynamic therapy: a hot topic in dermato-oncology (review). Oncol Lett. 2019:17(5):4085-93. https://doi.org/10.3892/ol.2019.9939.

4. Celli JP, Spring BQ, Rizvi I, Evans CL, Samkoe KS, Verma S, et al. Imaging and photodynamic therapy: mechanisms, monitoring, and optimization. Chem Rev. 2010;110(5):2795-838. https://doi.org/10.1021/cr900300p.

5. Josefsen LB, Boyle RW. Photodynamic therapy: novel third-generation photosensitizers one step closer? Br J Pharmacol. 2008;154(1):1-3. https:// doi.org/10.1038/bjp.2008.98.

6. Bonnett R. Chemical aspects of photodynamic therapy; 2000. https://doi. org/10.1201/9781482296952.

7. Lazzeri D, Durantini EN. Synthesis of meso-substituted cationic porphyrins as potential photodynamic agents. Arkivoc. 2003;2003(10):227-39. https://doi. org/10.3998/ark.5550190.0004.a23.

8. Couto GK, Pacheco BS, Borba VM, Junior JCR, Oliveira TL, Segatto NV, et al. Tetra-cationic platinum(II) porphyrins like a candidate photosensitizers to bind, selective and drug delivery for metastatic melanoma. J Photochem Photobiol B Biol. 2020;202:111725. https://doi.org/10.1016/j.jphotobiol.201 9.111725.

9. Bakry R, Vallant RM, Najam-ul-Haq M, Rainer M, Szabo Z, Huck CW, et al. Medicinal applications of fullerenes. Int J Nanomedicine. 2007;2(4):639-49.

10. Milanesio M, Alvarez M, Rivarola V, Silber J, Durantini E. Porphyrin-fullerene C60 dyads with high ability to form photoinduced charge-separated state as novel sensitizers for photodynamic therapy. Photochem Photobiol. 2005; 81(4):891-7. https://doi.org/10.1562/2005-01-24-RA-426R.1.

11. Durantini J, Otero L, Funes $M$, Durantini E, Fungo F, Gervaldo M. Electrochemical oxidation-induced polymerization of 5,10,15,20-tetrakis[3-(Nethylcarbazoyl)]porphyrin. Formation and characterization of a novel electroactive porphyrin thin film. Electrochim Acta. 2011;56(11):4126-34. https://doi.org/10.1016/j.electacta.2011.01.111.

12. Ferreyra DD, Spesia MB, Milanesio ME, Durantini EN. Synthesis and photodynamic properties of 5,10,15,20-tetrakis[3-(N-ethyl-Nmethylcarbazoyl)]chlorin and its analogous porphyrin in solution and in human red blood cells. J Photochem Photobiol A Chem. 2014;282:16-24. https://doi.org/10.1016/j.jphotochem.2014.02.004.

13. Ferreyra DD, Reynoso E, Cordero P, Spesia MB, Alvarez MG, Milanesio ME, et al. Synthesis and properties of 5,10,15,20-tetrakis[4-(3-N,Ndimethylaminopropoxy)phenyl] chlorin as potential broad-spectrum antimicrobial photosensitizers. J Photochem Photobiol B Biol. 2016;158:24351. https://doi.org/10.1016/j.jphotobiol.2016.02.021.

14. Quiroga ED, Mora SJ, Alvarez MG, Durantini EN. Photodynamic inactivation of Candida albicans by a tetracationic tentacle porphyrin and its analogue without intrinsic charges in presence of fluconazole. Photodiagn Photodyn Ther. 2016;13:334-40. https://doi.org/10.1016/.jpdpdt.2015.10.005.

15. Caminos DA, Durantini EN. Synthesis of asymmetrically meso-substituted porphyrins bearing amino groups as potential cationic photodynamic agents. J Porphyr Phthalocyanines. 2005;9(05):334-42. https://doi.org/1 $0.1142 / S 1088424605000423$.

16. Ballatore MB, Spesia MB, Milanesio ME, Durantini EN. Synthesis, spectroscopic properties and photodynamic activity of porphyrin-fullerene C60 dyads with application in the photodynamic inactivation of Staphylococcus aureus. Eur J Med Chem. 2014;83:685-94. https://doi.org/1 0.1016/j.ejmech.2014.06.077.

17. Mora SJ, Milanesio ME, Durantini EN. Spectroscopic and photodynamic properties of 5,10,15, 20-tetrakis[4-(3-n,n-

dimethylaminopropoxy)phenyl]porphyrin and its tetracationic derivative in different media. J Photochem Photobiol A Chem. 2013;270:75-84. https:// doi.org/10.1016/j.jphotochem.2013.07.013.

18. Urtreger AJ, Ladeda VE, Puricelli LI, Rivelli A, Del Carmen VM, De Lustig ES, et al. Modulation of fibronectin expression and proteolytic activity associated with the invasive and metastatic phenotype in two new murine 
mammary tumor cell lines. Int J Oncol. 1997;11(3):489-96. https://doi.org/1 0.3892/ijo.11.3.489.

19. Denizot F, Lang R. Rapid colorimetric assay for cell growth and survival. Modifications to the tetrazolium dye procedure giving improved sensitivity and reliability. J Immunol Methods. 1986;89(2):271-7. https://doi.org/10.101 6/0022-1759(86)90368-6.

20. Taylor R. Interpretation of the correlation coefficient: a basic review. J Diagn Med Sonogr. 1990;6(1):35-9. https://doi.org/10.1177/875647939000600106.

21. Schindelin J, Arganda-Carreras I, Frise E, Kaynig V, Longair M, Pietzsch T, et al. Fiji: An open-source platform for biological-image analysis. Nat Methods. 2012;9:676-82. https://doi.org/10.1038/nmeth.2019.

22. Workman P, Aboagye EO, Balkwill F, Balmain A, Bruder G, Chaplin DJ, et al. Guidelines for the welfare and use of animals in cancer research. $\mathrm{Br}$ J Cancer. 2010;102(11):1555-77. https://doi.org/10.1038/sj.bjc.6605642.

23. Smith A, Morgan WT. Hemopexin-mediated transport of heme into isolated rat hepatocytes. J Biol Chem. 1981;256(21):10902-109. https://doi.org/10.101 6/S0021-9258(19)68530-3.

24. Hall HK. Correlation of the base strengths of amines. J Am Chem Soc. 1957; 79(20):5441-4. https://doi.org/10.1021/ja01577a030.

25. Rodriguez L, Vallecorsa P, Battah S, Di Venosa G, Calvo G, Mamone L, et al. Aminolevulinic acid dendrimers in photodynamic treatment of cancer and atheromatous disease. In: Photochemical and Photobiological Sciences; 2015. p. 1617-27.

26. Liu JH, Cao L, Luo PG, Yang ST, Lu F, Wang H, et al. Fullerene-conjugated doxorubicin in cells. ACS Appl Mater Interfaces. 2010;2(5):1384-9. https://doi. org/10.1021/am100037y.

27. Mamone L, Ferreyra DD, Gándara L, Di Venosa G, Vallecorsa P, Sáenz D, et al. Photodynamic inactivation of planktonic and biofilm growing bacteria mediated by a meso-substituted porphyrin bearing four basic amino groups. J Photochem Photobiol B Biol. 2016;161:222-9. https://doi.org/10.1 016/j.jphotobiol.2016.05.026.

28. Berg K, Selbo P. Macromolecular therapeutics. The cellular membrane as a barrier o therapeutic effectiveness. In: Kadish K, Smith K, Guilard R, editors. Handbook Of Porphyrin Science: With Applications To Chemistry, Physics, Material Sciences, Engineering, Biology and Medicine. London: World Scientific Publishing Co. Pte. Ltd; 2016. p. 249-50.

29. Fontanelli R, Papadia A, Martinelli F, Lorusso D, Grijuela B, Merola M, et al. Photodynamic therapy with M-ALA as non surgical treatment option in patients with primary extramammary Paget's disease. Gynecol Oncol. 2013; 130(1):90-4. https://doi.org/10.1016/j.ygyno.2013.04.008

30. Gold MH, Bradshaw VL, Boring MM, Bridges TM, Biron JA, Lewis TL. Treatment of sebaceous gland hyperplasia by photodynamic therapy with 5-aminolevulinic acid and a blue light source or intense pulsed light source. J Drugs Dermatol. 2004;3(6 Suppl). PMID: 15624735.

\section{Publisher's Note}

Springer Nature remains neutral with regard to jurisdictional claims in published maps and institutional affiliations.

Ready to submit your research? Choose BMC and benefit from:

- fast, convenient online submission

- thorough peer review by experienced researchers in your field

- rapid publication on acceptance

- support for research data, including large and complex data types

- gold Open Access which fosters wider collaboration and increased citations

- maximum visibility for your research: over $100 \mathrm{M}$ website views per year

At BMC, research is always in progress.

Learn more biomedcentral.com/submissions 